\title{
A AGRESSÃO SEXUAL NA ADOLESCÊNCIA: UM DESTINO DA HIPERATIVIDADE?
}

Jean Yves Chagnon

Psicólogo clínico; psicanalista; perito judiciário em Bourges, França. "Maître de Conférence" HDR, Laboratório de Psicologia Clínica e Psicopatologia, Instituto de Psicologia, Paris 5 - René Descartes, Paris, França.

Tradução: Pedro Henrique Bernardes Rondon

RESUMO: O artigo apresenta os resultados de uma pesquisa sobre adolescentes autores de atos de agressão sexual, examinados no âmbito de perícias judiciárias. Esses sujeitos tinham sido crianças instáveis, agitadas ou, ainda, hiperativas. Procura-se, então, explicar de que maneira a hiperatividade infantil, dificuldade de tratar mentalmente as excitações pulsionais, constitui fator de risco de agressão sexual na adolescência. A noção de narcisismo fálico permite esclarecer os impasses identificatórios e a dificuldade de compor com a mutualidade dos desejos.

Palavras-chaves: Adolescência, agressão sexual, clínica e psicopatologia psicanalítica, hiperatividade, narcisismo fálico.

ABSTRACT: Sexual assault in adolescence: a fate for hyperactivity? This paper presents the results of a research about adolescents having perpetrated sexual assault, met in the precinct of judiciary expertise. These subjects had been instable children, agitated or yet hyperactive. The author tries then to explain how infantile hyperactivity, the difficulty to mentally deal with drive excitations, can be a risk factor of sexual assault in adolescence. The notion of phallic narcissism allows illuminating the identificatory deadlocks and the trouble to reconcile with the mutuality of desires.

Keywords: Adolescence, sexual assault, psychoanalytical clinic and psychopathology, hyperactivity, phallic narcissism.

\section{INTRODUÇÃO}

Já há muitos anos trabalho a partir de uma clínica pericial judiciária, na descrição clínica e psicopatológica dos autores - adultos inicialmente, depois adolescentes - de agressões sexuais (CHAGNON, 2000, 2004, 2005, 2007). Inscrito na corrente psicodinâmica organizada em torno de C. Balier (1988, 1996, 2005) e A. Ciavaldini $(1999,2000)$, tive a oportunidade, depois de muitos outros, de "libertar" a passagem ao ato sexual violenta de sua dimensão de sintoma de uma estrutura 
perversa considerada “irrecuperável”, para mostrar como é frequente que tal passagem ao ato adquira o valor de arranjo defensivo ante as angústias narcísicas, depressivas ou mais francamente psicóticas, pertencendo ao vasto quadro dos distúrbios narcísicos-identitários (ROUSSILLON, 1999). Trata-se de uma concepção “econômico-dinâmica” que valoriza a noção de funcionamento psíquico e, em particular, a noção de defesas, mais do que uma concepção estrutural congelada, deficitária ou pouco otimista quanto à capacidade de mudança.

$\mathrm{Na}$ adolescência a questão do diagnóstico e do prognóstico, explicitamente colocada ao perito, se revela crucial, porquanto a passagem ao ato, muitas vezes consubstancial à própria adolescência (MARTY, 2999) não adquire as mesmas significações que no adulto, e pode se estender das variações do normal ao patológico mais preocupante. A questão que se apresenta diz respeito, de saída, ao caráter organizador ou não da conduta comportamental sobre o funcionamento psíquico que, dessa maneira, pode perder suas potencialidades adolescentes de geração de novidades, para se enquistar numa ruptura de desenvolvimento (LAUFER e LAUFER, 1989), principal perigo de toda sintomatologia na adolescência: a psicopatologia grave do adulto pode ser considerada como fracasso dos processos de subjetivação adolescente (CAHN, 1998).

Dois fatos clínicos vão apresentar aquilo que proponho. Por um lado, a maioria dos agressores sexuais se lembra, quando bem querem reconhecer isso ou pensar a respeito, de ter cometido seus primeiros atos de delinquência sexual na adolescência ou pouco depois, havendo algumas vezes, mas não sempre, uma escalada nos atos, indo da bolinação ao estupro, às vezes com ideias - e mais raramente com alguma realização — de homicídio. Por outro lado, a questão das agressões sexuais na adolescência nesses últimos anos veio para o primeiro plano do palco da mídia em consequência da tomada de consciência da importância dos estupros coletivos, mais conhecidos sob o nome de 'curras', o que obrigou os clínicos a se debruçarem sobre um fenômeno, decerto não desconhecido, mas negligenciado até então no nível dos estudos científicos, ainda que o fenômeno da violência em geral, dos distúrbios de comportamento e da delinquência de tipo psicopático tenha sido particularmente pesquisado, quase sempre pelos especialistas da psicopatologia da adolescência (JEAMMET, 1985 e 1997; MARTY, 2000, JEAMMET et al. 1998).

O aumento do número de adolescentes agressores sexuais junto aos quais me coube, a partir dos anos 2000, a missão de realizar perícias psicológicas, me permite efetuar uma pesquisa, em curso atualmente, sobre 20 adolescentes e/ou jovens adultos com idades de 12 a 20 anos, levados a exame por agressões sexuais ou estupros, pesquisa esta executada com metodologia plural (entrevistas semidiretivas, testes projetivos, respostas às três questões referentes ao registro do funcionamento psíquico; os determinismos psicológicos que podem ser re- 
construídos das passagens ao ato; o prognóstico de "readaptação”). ${ }^{1}$ Publicados em 2005, e depois retomados numa coletânea organizada sob a direção de F. Marty (2007), os primeiros resultados dessa pesquisa puseram diante de mim uma descoberta inesperada: a existência de um laço entre a instabilidade psicomotora, a agitação ou hiperatividade infantil, de acordo com uma terminologia contemporânea, e a potencialidade para desenvolver comportamentos sexuais agressivos na adolescência.

De fato, estudos epidemiológicos longitudinais anglo-saxões baseados no DSM IV, os quais, aliás, alimentaram o tão controvertido relatório do Inserm sobre os distúrbios de conduta na criança e no adolescente (2005) e citados por F. Bange e M.-C. Mouren (2005), apontam há muito tempo que a hiperatividade infantil é fator de risco em relação à sobrevinda de ulteriores distúrbios de conduta, talvez mesmo de distúrbios antissociais e criminosos. Os mesmos autores também evocam o fato de que os distúrbios psiquiátricos comórbidos com a hiperatividade são mais numerosos na idade adulta do que na criança: distúrbios de ansiedade, distúrbios do humor, distúrbios devidos ao abuso de substâncias psicoativas e por fim distúrbios de conduta e personalidade antissocial, dentre os quais a parafilia. Entretanto, esses estudos descritivos e estáticos, aliás tendenciosos por causa do postulado segundo o qual a hiperatividade é uma doença neurológica que escapa à psicopatologia, nada dizem quanto aos encadeamentos evolutivos que, de um fator de risco, fazem uma realidade preocupante na adolescência. Para os clínicos ligados à psicanálise, as modificações da agitação/hiperatividade que com muita frequência estão intrincadas com outras manifestações sintomáticas — facetas diferentes do mesmo quadro psicopatológico e que evoluem conforme as vicissitudes da história infantil do sujeito — só adquirem sentido quando relacionadas ao impacto do processo da adolescência sobre o próprio sujeito e seu ambiente, cuja capacidade de sobreviver vai ser fundamental.

Também vou tentar agora, por um lado, apreender as características clínicas e psicopatológicas dos agressores sexuais adolescentes encontrados, comparando-as aos escassos dados obtidos da literatura sobre esse tema e, por outro, recorrendo ao conceito de narcisismo fálico, dar conta dos riscos evolutivos da hiperatividade infantil em relação aos comportamentos sexuais violentos. Sobre este conceito já procurei realizar breve estudo histórico, antes de articulá-lo ao processo da adolescência, parcialmente mal-sucedido na maioria desses sujeitos.

\footnotetext{
${ }^{1}$ Esta última questão tem ainda mais peso nas perspectivas do juizado de menores, organizada depois da Constituição francesa de 1949 em torno do princípio de "proteger e prevenir", em que a busca de medidas educativas prevalece sobre a condenação penal, princípio regulamentar questionado pelos políticos por causa do alegado aumento da violência entre os jovens.
} 


\title{
I - QUEM SÃO OS AGRESSORES SEXUAIS NA ADOLESCÊNCIA?
}

Por ocasião da primeira conferência de consenso consagrada a "psicopatologia e tratamentos atuais dos autores de agressão sexual" (2001), foi lembrado que a população de crianças e adolescentes agressores sexuais era particularmente heterogênea no plano psicopatológico e no das características da conduta sexual.

\begin{abstract}
"Ante essa heterogeneidade, tenta-se estabelecer tipologias dos abusadores adolescentes em função das características clínicas dos autores, das características da própria agressão e dos dados biográficos e da anamnese, a fim de avaliar melhor as possibilidades de mudança e de melhor discriminar os riscos de recidiva; entretanto, até aqui nenhuma dessas tipologias foi validada por algum estudo prospectivo suficientemente prolongado." (Conferência de Consenso, 2001, p.562)
\end{abstract}

O debate tem importância porque é sabido que determinadas condutas sexuais desviantes podem não ser mais do que um acidente de percurso, talvez mesmo uma manifestação um pouco ruidosa de sexualidade adolescente ainda mal desprendida de seus aspectos de sexualidade infantil, perversa polimorfa por definição, ou ao contrário, ponto de partida de conduta desviante repetitiva na idade adulta. A questão do prognóstico, como já lembrei antes, que é proposta na perícia psicológica, revela-se tanto crucial no plano psicopatológico, quanto discutível do ponto de vista ético, uma vez que são conhecidos os efeitos negativos da comunicação de diagnóstico e de prognóstico desfavoráveis.

É costumeiro distinguir, no que se refere às agressões sexuais na adolescência, os estupros individuais - no que tange a crianças ou a mulheres jovens - dos estupros coletivos - dentre os quais as curras - sendo que estes últimos representam $60 \%$ dos casos, contra $40 \%$ dos primeiros. Segundo C. Legendre \& C. Balier $(2005,2003)$, os estupros coletivos deveriam ser situados numa dinâmica psíquica própria da adolescência, e isso num contexto de disfunção parental, de carências identificatórias e de descontinuidades biográficas. Corresponderiam a uma busca atuada de identidade sexual nos sujeitos para quem, ante a incerteza adolescente da sexuação, a fragilidade narcísica exigiria uma passagem ao ato diante do grupo para corroborar uma identificação sexual masculina. O grupo teria efeito de desinibição e proporcionaria, de maneira violenta e transgressora, possibilidade de afirmação de si mesmo e de identificação pela dominação-possessão da vítima, quase sempre pessoa próxima dos autores. Foi possível evocar uma dimensão iniciática aparentada aos ritos de passagem. Sem banalizar o fenômeno, tratar-se-ia antes de tudo de um fenômeno de grupo que não se refere apenas aos bairros difíceis, mas também aos bairros mais ricos (nas noitadas regadas e enfumaçadas), e a maioria dos sujeitos envolvidos, individualmente não teria tido os mesmos comportamentos. Foi acrescentado que 
essas condutas "não parecem depender de distúrbios específicos das condutas sexuais" (Conferência de Consenso, 2001, p.562) — o que é discutível — bem como que exigem respostas adequadas no plano penal e no educativo - algo com que só podemos mesmo concordar.

Na minha pesquisa, tive oportunidade de encontrar seis adolescentes que atuaram em "reunião", num caso de conformação incomum, uma vez que envolvia dois irmãos (psicopatas) que atacaram sua própria irmã. Se estes dois últimos dependiam de um contexto sociofamiliar muito carente em que a incestualidade (RACAMIER, 1995) caracterizava as relações familiares, os outros quatro adolescentes provinham de famílias abastadas no plano sociocultural e econômico. As agressões sexuais de que se trata eram antes indelicadas e coercitivas do que violentas em relação às jovens agredidas e apareciam como acontecimentos pontuais e sem verdadeiro potencial de repetição, ainda quando as vítimas eram tratadas com desprezo e tinham sua alteridade pouco reconhecida. Embora não negassem seus atos que resultavam de circunstâncias singulares e complexas em que a dimensão estrutural ${ }^{2}$ sozinha não era suficiente para explicar o emprego da passagem ao ato (grupo, multidão, festividade, embriaguês alcoólica, utilização de drogas, etc.), em compensação, eles negavam o caráter de constrangimento ou de surpresa, evacuando facilmente sua própria pulsionalidade para projetá-la no grupo ou na vítima. Para dois deles tratava-se de sua primeira experiência sexual, iniciática, portanto; para outros dois as agressões se inscreviam num ativismo sexual pouco escrupuloso que prolongava a instabilidade prévia motora e afetiva: as moças eram consideradas objetos de consumo rápido, e descartáveis, contornando dessa maneira o temor recorrente do aprisionamento numa ligação estável, o que correspondia à mentalidade "machista" dos grupos que eles frequentavam.

As agressões sexuais e estupros individuais cometidos por um adolescente dependem, sempre segundo C. Legendre \& C. Balier $(1995,2003)$, de tal variedade de condutas que fica impossível qualquer generalização. Nestes casos é que encontraríamos os distúrbios mais importantes no processo da adolescência, em especial o trabalho de separação-individuação e de desidentificação quanto aos objetos primários, engendrando angústias depressivas ou de anulação próximas da psicose, angústias colmatadas pelas passagens ou pelo recurso ao ato, dentre os quais os atos sexuais muitas vezes estão imersos numa patologia de dependência maciça.

Na minha própria pesquisa fiz constatações semelhantes: do ponto de vista clínico, a grande diversidade de situações impede efetivamente a generalização.

\footnotetext{
${ }^{2}$ No plano diagnóstico, dois desses sujeitos apresentavam organização (neurose) de caráter narcísico fálico; outro, uma patologia limite franca, e o último um caráter fóbico-obsessivo muito rígido.
} 
De fato há poucas semelhanças entre esse menino de 12 anos que tenta penetrar uma "namorada" de 10 anos sem conseguir, depois de lhe ter oferecido guloseimas (!), ou entre esse menino que logo fará 14 anos e arrasta seu primo pré-púbere para brincadeiras que este não deseja, e os casos de estupradores de adolescentes ou de mulheres adultas jovens. Os primeiros remetem às falhas educativas parentais manifestas, uma vez que esses sujeitos, em início de adolescência, não apresentam distúrbios psicopatológicos importantes, o que também não significa que seja conveniente banalizar esses atos, porquanto não sendo reconhecidos podem tornar-se organizadores da adolescência que está chegando. Mas esses casos são minoritários na minha turma: os demais (12 casos, dos quais quatro eram casos de incesto irmão-irmã) dependem antes de sujeitos já perturbados psiquicamente em graus diversos: distúrbios da personalidade limite ou borderline, psicopatias com ou sem arranjos perversos, pré-psicoses, um caso de psicose infantil. Se na história deles é frequente encontrarmos, como no caso de Laurent, ${ }^{3}$ a suposição de um estupro ou de uma agressão sexual sofrida ou ainda uma atitude sedutora crônica, estes só adquirem sentido quando referidos ao contexto familiar ou social que muitas vezes lhes deu "permissão": de fato, são laços de ternura que falharam quanto a estruturar o sujeito e a intrincar suas pulsões, e a destrutividade emerge menos como pulsão liberada do que como ameaça à identidade (JEAMMET, 1997) na ocasião do a posteriori pubertário violento e fundamentalmente traumático (MARTY, 2000).

Vou acrescentar que a maioria desses adolescentes, incluídos aqueles inteligentes e de condição sociofamiliar elevada, quer sejam estupradores individuais ou em grupo, se mostram, mais do que os adultos, incapazes de falar de seu ato — quando não o negam — de apreender os prolegômenos e as consequências afetivas, e especialmente incapazes de se identificar com a vítima e com sua dor: a simbolização é frágil ou falha, mas também a identificação do afeto, o que A. Ciavaldini (1999) chama de carência de tato psíquico e, mais recentemente, de 'inacabamento do afeto' (idem, 2005, 2006). Não podendo identificar suas inquietações afetivas, esses sujeitos não podem identificar-se às do outro, o que muitas vezes é atribuído à frieza, à inafetividade e à imoralidade malignas do psicopata de K. Schneider (1923). Por vias diferentes das de A. Ciavaldini, uma vez que resultam da psiquiatria infantil psicanalítica e da psicossomática, cheguei às mesmas conclusões que ele. De fato, uma surpresa foi constatar que três quartos desses sujeitos (qualquer que fosse o tipo de agressão: estupro ou agressão "simples", sozinho ou em grupo) se descreviam como tendo sido crianças instáveis, agitadas, talvez mesmo - alguns empregavam o termo — hiperativos,

\footnotetext{
${ }^{3}$ Caso apresentado e discutido diversas vezes (CHAGNON, 2004, 2005b, 2007), ilustrando a colmatagem de angústias psicóticas por meio das agressões sexuais.
} 
desde sua mais tenra infância (alguns, desde antes dos 3 anos). Interrogando retrospectivamente a minha turma de adultos, encontrei neles a mesma proporção. A descrição dessa agitação se revelou característica: são crianças excitadas, instáveis, sempre em movimento, impulsivas, desatentas, "do contra”. Aqueles que virão a se tornar psicopatas rapidamente formaram para si mesmos uma identidade de alunos negligentes e de chefes de bandos de marginais, subsidiando mal uma autoestima, que fica sem firmeza. A espera, a demora e, no fundo, a dependência e a passividade diante do outro se tornaram pouco a pouco insuportáveis para eles, donde sua dificuldade de alcançar sucesso numa escolaridade adornada de diversas repetições de séries e expulsões de escolas. Em sua maioria eram adolescentes que buscavam sensações fortes e violentas desde muito cedo (velocidade, motocicleta, esportes radicais, músicas de tipo hard, etc.), muitas vezes acompanhadas de ingestão de tóxicos (álcool, haxixe, cocaína). Quanto aos menos perturbados, a instabilidade psicomotora precoce em relação com forte excitação pulsional largamente alimentada por ambientes liberais e pouco autoritários não tinha sido seguida de incidentes verdadeiramente nefastos sobre sua escolaridade primária, simplesmente tinham trabalhado sem interesse, sem prazer e, não tendo desenvolvido nenhum prazer de funcionamento mental suficiente, só no curso médio se viram em dificuldades. No entanto, já suportavam mal as esperas, a passividade e a solidão (por exemplo, as horas de sesta ou os momentos de descanso) e desde muito cedo foram esportistas e grandes competidores. Observemos a diversidade desses esportes (três ou quatro durante a infância, para uma mesma criança) e o gosto acentuado pelos de tipo radical, pelas noitadas, pela velocidade, etc. Além disso, eram grandes consumidores de filmes de ação e de jogos eletrônicos. Essa constatação clínica justifica agora que façamos um rodeio em direção à psicopatologia da hiperatividade, a fim de compreendermos como esta pode desde então evoluir para modos de agir sexuais violentos na adolescência, modos de agir que tomam o lugar de uma elaboração psíquica (afetiva) falha da relação com o outro.

\section{II - A HIPERATIVIDADE INFANTIL ${ }^{4}$}

É sabido que hoje em dia essa noção de hiperatividade divide a comunidade psi, alguns querendo fazer dela um distúrbio neurológico isolado de qualquer dimensão psicológica, como se não se pudesse ao mesmo tempo dispor de um funcionamento mental e de um funcionamento cerebral que não se sobrepõem mutuamente. De fato sabe-se que há muito tempo reina uma dualidade de

\footnotetext{
${ }^{4}$ Abordei estas questões em dois artigos: Chagnon, J-Y (2005) "Hyperactifs ou hypopassifs? Hiperactivité infantile, agressions sexuelles à l'adolescence et nouveau malaise dans la civilisation", Psychiatrie de l'enfant, XLVIII, 1, 2005, 31-88; (2006) "Plaidoyer pour um abord psychopathologique de l’hyperactivité”, Perspectives Psy, n. IV-2006.
} 
concepções entre a escola europeia, e francesa em particular, que prefere falar de instabilidade psicomotora ou de agitação, compreendidas como sintomas que muitas vezes fazem parte de um quadro psicopatológico complexo, e a escola norte-americana que descreve uma hipercinesia que se torna hiperatividade — com ou sem distúrbios de atenção — concebida como entidade autônoma que se supõe ter origem neurobiológica (GOLSE \& DELION, 2003). Acrescentemos que o diagnóstico de hiperatividade, segundo o DSM IV, deve ser efetuado independentemente de qualquer afecção psiquiátrica (distúrbios tímicos, ansiosos, da personalidade) e deve ser diferenciada da instabilidade secundária em condições ambientais defeituosas, o que causa perplexidade quanto à cegueira daqueles que sustentam tal concepção em determinadas circunstâncias. De fato, opera-se uma comunidade de recusa entre esses sujeitos e os modelos médicos que chamei de "duros", que resistem à abordagem psicopatológica, recusa referida - qualquer que seja sua etiologia - à existência de um mundo interno, de uma interioridade psíquica povoada de representações carregadas de afeto, simbolizadas, que esses sujeitos temem e das quais fogem em direção ao mal-estar e aos riscos da desorganização traumática em que as percepções internas fazem incorrer: nada dentro, tudo fora. Um levantamento epidemiológico citado por Mises (2004) e realizado com o auxílio da Classificação Francesa dos Distúrbios Mentais da Criança e do Adolescente mostrava que em dois terços dos casos a instabilidade psicomotora se ligava a outra patologia subjacente, fundamentalmente de tipo limite, enquanto em um terço dos casos o diagnóstico de hiperatividade era efetuado como categoria principal. Foi, portanto, para localizar melhor a especificidade dessa psicopatologia hiperativa "essencial" que se anexaram trabalhos recentes de referência psicanalítica (BERGER, 1999; MÉNÉCHAL et al., 2001, JOLY et al., 2005) que R. Mises magistralmente resumiu em seu prefácio ao livro de J. Ménechal (2001). Destaca-se daí que se a hiperatividade algumas vezes pode ser compreendida com referência à defesa maníaca contra a depressão, outros modelos teóricos vão surgir apoiados nas contribuições dos psicossomatistas ou ainda nas de psicanalistas empenhados no tratamento de "casos difíceis" que, em função de traumatismos do início da vida (ROUSSILLON, 1999), apresentam fracassos da mentalização e da simbolização e uma pluralidade de expressão sintomática tanto do lado do corpo quanto do lado do agir (a motricidade se situando na encruzilhada das duas dimensões) do qual não está excluído o componente perverso.

Minha posição (CHAGNON, 2005 e 2006) se inscreve nesse movimento: penso que a hiperatividade deveria sempre ser ressituada num contexto mais global da disfunção psíquica essencialmente (embora não exclusivamente — há também casos em que se verifica que há psicoses) referida a uma organização 
psíquica do tipo limite (Mises, 1990) ${ }^{5}$ ou pré-psicótica (DIATKINE, 1969), na qual os distúrbios propriamente mentais, nos casos de hiperatividade "essencial”, estão mascarados, silenciosos ou brancos (consequentemente subdiagnosticados). Esses sujeitos se revelavam relativamente intolerantes à mentalização uma vez que esta é maciçamente angustiante ou é fonte de desorganização traumática. Fracassando em suas funções de tratamento da excitação, o psiquismo recorreria de preferência aos registros perceptivo-motores e comportamentais, correndo o risco de uma estruturação progressiva numa neoidentidade hiperativa, implicando a resposta do ambiente submetido a encarregar-se das falências do mundo interno. Quaisquer que sejam as modalidades defensivas que subtendam a agitação (defesas maníacas, analidade primária evacuadora, procedimentos autocalmantes, etc.), a excitação pulsional não pode ser resolvida pela via mental (ligação representações/afetos) e se descarrega na motricidade, no comportamento e às vezes no agir, convocando o ambiente paradoxalmente mobilizado para conter essa excitação e rejeitado pelas ameaças de intrusão que a ligação ao outro, impensável, comporta. Dessa maneira, propus a ideia de uma inversão semântica (hiperatividade ou hipopassividade?) para dar destaque à recusa ou incapacidade desses sujeitos masculinos quanto a ter acesso a uma posição passiva secundária (aquela ligada ao Édipo negativo provoca demais a angústia de castração), mas, sobretudo, uma passividade primária, aquela evocada por C. Chabert (2003), que neles remeteria demais a uma ameaça de passivização anuladora no contato com o objeto materno, uma vez que os traumatismos primários são maciços. 6 Ser ninado, acariciado, tocado, afetado pelo outro, implica uma dependência mortífera recusada e combatida por uma frente de recusa anti-introjetiva (não quero nada do outro, fazendo isso eu não me construo), recusa constitutiva da hiperatividade tornada envoltório ou película identitária fragilíssima e ao mesmo tempo extremamente resistente, privando-os de qualquer contato com o registro do feminino neles, com sua interioridade. Seu psiquismo achatado, sem espessura, não se organiza em tópica constituída, sem falar da falência da estruturação pós-edípica e, portanto, do trabalho da latência, constitutivos do narcisismo secundário construído aqui contra o objeto: para sua própria regulação pulsional e alimentação narcísica, esses sujeitos ficarão dependentes do enquadre, ao mesmo tempo que o negam.

\footnotetext{
${ }^{5}$ Se incluirmos as neuroses de caráter ou as neuroses de comportamento descritas pelos psicossomatistas (ou suas formas prévias na criança) como o próprio Mises propõe em seu livro sobre as patologias limites.

${ }^{6}$ Pelos quais a mãe está longe de ser sempre responsável: estou pensando nas doenças do início da vida que impõem cuidados intrusivos.
} 


\section{III - O NARCISISMO FÁLICO}

Observemos que já há muito tempo esses fatos eram bem conhecidos dos psicossomatistas, que diziam que esses sujeitos inaptos ao repouso e candidatos potenciais à somatização "queimavam a vela pelas duas extremidades". M. Fain (1990) fez a ligação com a delinquência num artigo que muito me inspirou, intitulado "Virilité et antihystérie: les rouleurs de mécanique". Para esse autor, a delinquência do tipo arrogante são neuroses de comportamento ou neuroses de caráter narcísico-fálico que valorizam enormemente o ativo, o viril, desprezando o feminino, o passivo, atribuído a castrado, a mortífero, passividade tanto mais odiada e perseguida com obstinação nas pessoas femininas quanto é invejada como fator de completude. Foi assim que vim a trabalhar a questão do narcisismo fálico, que já tinha visto (CHAGNON, 2000) ser interessante para descrever o movimento de restauração narcísica compreendido na passagem ao ato sexual delinquente, ${ }^{7}$ bem como que era importante procurar sua gênese como conceito na história das ideias psicanalíticas: não posso retomar aqui todos esses trabalhos apresentados em outro lugar (idem, 2005a) e, para os presentes propósitos, vou me restringir às concepções de M. Fain $(1985,1991)$.

Esse autor de fato vai trazer numerosos esclarecimentos clínicos e teóricos a essa noção de narcisismo fálico, a partir do estudo de sujeitos somatizantes que não toleram o repouso nem as posições passivas. Neles há, segundo o autor, uma perturbação do duplo retorno da pulsão ${ }^{8}$ (atividade $\longrightarrow$ passividade: eu descanso, cuidam de mim) por causa de traumatismos do início da vida, o que engendra uma distorção na constituição do Ego, um inacabamento pulsional. A percepção da falha na personalidade deles sustenta os efeitos de um antigo trauma que agravou as possibilidades de satisfação passiva, o que se traduz no caso deles por excitação crônica. A atividade se torna o próprio símbolo da falta que procura dissimular, símbolo que obriga a uma atividade sem fim. É claro que se vê bem todo o interesse desse modelo para a compreensão dos hiperativos. Para o autor, é possível encontrar dois tipos clínicos: o primeiro diz respeito a sujeitos cujo inacabamento pulsional está centrado no tempo (b) (eu me) e que desenvolvem comportamentos hiperativos e ideais de autossuficiência. Suas identificações secundárias (apoio do narcisismo secundário) não decorrem de

\footnotetext{
${ }^{7}$ Por vias diversas, F. Neau $(2001,2005)$ chegou a uma ideia próxima de um "masculino maníaco" construído em cima do modelo oposto de um "feminino melancólico" (CHABERT, 2003).

${ }^{8}$ Mecanismo de duplo retorno ativo-passivo e em seu contrário, descrito por Freud (1915) anterior ao recalcamento, e que permite concentrar-se no narcisismo. Esse mecanismo se decompõe em três tempos: (a) eu o (seguido de um verbo na voz ativa); (b) eu me (seguido pelo mesmo verbo na voz passiva); (c) ele me (verbo na voz ativa). A fantasia, com sua estrutura ternária (sujeito-verbo-objeto), põe em cena esses sucessivos retornos (cf. "uma criança é espancada").
} 
uma sexualização [o tempo (c)] — ele me proíbe, por exemplo — não é seguido por um retorno em direção ao tempo (b) — identificatório: eu me proíbo); aparentemente essas identificações secundárias serão narcisicamente investidas, mas vão ficar "sem espessura”. Não são de fato personalidades narcísicas, porquanto têm necessidade toxicomaníaca de admiração, e esta não se transforma em autoestima. Não podem dar de si mesmos senão uma imagem ativa e, no extremo, sua incapacidade de suspender a atividade pode desembocar em comportamentos suicidas. Os sujeitos do segundo tipo subordinam sua necessidade de atividade a sistemas externos (modelos sociais e operatórios para as neuroses de comportamento; grupo ou ideologia para os delinquentes) e parecem buscar o tempo (c) do duplo retorno que lhes terá faltado. Em suma, para M. Fain,

“o narcisismo fálico se opõe ao narcisismo secundário positivo e restaurador. Fundamentado na negação, talvez mesmo na recusa de uma falta, obriga o sujeito a construir-se em cima de ideais que não têm a função organizadora e protetora de um verdadeiro superego, este herdeiro do complexo de Édipo. O superinvestimento da atividade é o componente fundamental do narcisismo fálico que pode terminar numa verdadeira perversão das pulsões de conservação." (AISENSTEIN, 2000, p.58)

Nessa perspectiva o caráter narcísico fálico consiste menos numa fixação ao complexo de castração e numa defesa contra a posição feminina-passiva, inaceitável para o Ideal do Ego masculino, do que na inacessibilidade à passividade em consequência de traumas do início da vida. O narcisismo fálico nasce dessa tentativa de recusar a realidade do sentimento de incompletude que resulta desses inacabamentos. Apanhado dentro das coordenadas do complexo de castração que confronta à diferença dos sexos e à ausência do pênis na menina, o sujeito narcísico fálico fica fixado aí a uma concepção fálico-castrada da diferença entre os sexos (masculino = ativo, fálico; feminino = passivo, castrado) que fecha o caminho que leva às identificações bissexuais e à aceitação de uma parte de feminilidade em si mesmo — donde a necessidade compulsiva incessante de atividade, e o desprezo pelo "passivo".

\section{IV - A HIPERATIVIDADE À PROVA DA ADOLESCÊNCIA}

Findo esse rodeio clínico e psicopatológico pela hiperatividade, bem como o rodeio metapsicológico pelo narcisismo fálico, fica possível retornar, numa perspectiva transnosográfica, ao encontro entre esses sujeitos $\operatorname{agitados}^{9}$ e a

\footnotetext{
${ }^{9}$ Até aqui deixei de lado deliberadamente os cinco casos de adolescentes agressores sexuais que não eram hiperativos na infância. Estes antes correspondem àquilo que $\mathrm{S}$. Lemitre e R. Coutanceau (2006) descreveram sob o ponto de vista da dificuldade de regulação das emoções, da integração do corpo sensorial e da patologia da ação nos adolescentes fóbicoobssessivos ou imaturos e inibidos. A clínica "da agressão" é diferente, uma vez que nem sempre diz respeito a uma mulher jovem (bolinação furtiva de crianças, exibicionismo, agressões a um irmão, etc.).
} 
adolescência. P. Jeammet nos mostrou sem cessar que esta questionava a qualidade dos arranjos psíquicos anteriores, e especialmente a qualidade da regulação narcísica que resultou da primeira infância e da latência, a dependência infantil que não foi elaborada (JEAMMET \& CORCOS, 2005). Não vou voltar em minúcias às tarefas características da adolescência, esquematicamente situadas, uma delas num eixo narcísico (integrar uma nova identidade sexuada), a outra num eixo pulsional-objetal (encontrar o outro em sua dimensão de alteridade, complementar e diferente). Segundo R. Diatkine, "a passagem do investimento de objetos fantasísticos - aqueles que só estão aí para nossa exclusiva satisfação - para objetos externos, é a transformação mais importante dessa fase, tanto no território da criatividade quanto no da vida amorosa” (DIATKINE, 1985, p.1081). A possibilidade de realizações sexuais com um parceiro não imaginário põe o sujeito em confronto com a solidão, e implica renúncias múltiplas: aceitar que o outro tem um corpo, um psiquismo, desejos próprios e mais ainda que este não seja objeto de amor absoluto, totalmente satisfatório e portanto imediatamente disponível, o que implica a implantação de estratégias de aproximação que os agressores sexuais têm dificuldade para efetuar.

De fato, nos sujeitos agitados que na adolescência se tornaram agressores sexuais, quaisquer que sejam suas estruturas psíquicas, as duas tarefas narcísicas e objetais adquirem características singulares, e talvez mesmo fracassem em proporções variáveis. A identidade masculina se rebate sobre a identidade fálica: esta é a razão pela qual a ideia de afirmação masculina deveria ser matizada em determinados casos de estupros coletivos, uma vez que o masculino sempre se articula com o feminino nos adolescentes normativos. A dimensão "ambiciosa”, em movimento, do comportamento desses meninos que são agitados desde sua mais tenra idade, transposta para a atividade sexual-fálica, vem evidenciar o fracasso da transformação necessária do registro narcísico em registro erótico, trabalho da adolescência masculina. Esse adolescente sofre para ter acesso à diferença-complementaridade dos sexos, bem como para "desfalicizar seu pênis" (GUTTON, 1991), para fazer deste um órgão erótico masculino, ponte de uma junção emocional compartilhada com o outro diferente. O pênis, temporária ou definitivamente, fica sendo uma arma a serviço da afirmação da potência fálica, ou seja, do narcisismo exclusivo, mas de um narcisismo hemorrágico, uma vez que nunca é suficientemente alimentado a partir de dentro.

Quando no encontro com o outro - fonte de excitações mal representadas e, sobretudo, mal localizadas (dentro ou fora?) — esse encontro é dificultado por causa da platitude, da falta de profundidade do espaço psíquico, da pobreza das identificações introjetivas. É frequente que esses sujeitos nunca tenham podido ser afetados pelo outro, nem tenham conseguido organizar devaneios sobre o objeto que virá, condição para a implantação de uma conduta adaptada: 
a sedução de boa qualidade que implica a fantasmatização, ou seja a espera, a demora, e portanto a renúncia ao imediatismo. Nos casos mais graves, o "esquema penetrante-penetrado" (BALIER, 1996) substitui a identificação e a empatia: trata-se de possuir, de dominar, mas sobretudo de inverter ativamente o sentido das excitações recebidas passivamente. Invadir, penetrar à força o corpo do outro é um movimento em espelho daquilo que foi vivido subjetivamente no contato com esse outro, já que faltam limites dentro/fora suficientemente seguros. O ato da penetração intrusiva toma o lugar de uma interpenetração de olhares suficientemente boa, constitutiva do fundo de si mesmo e, consequentemente, dos limites eu-não eu, porosos, nesse caso, por causa do predomínio da patologia de limites. Algumas ligações poderiam ainda ser lançadas com a identificação projetiva patológica, dita intrusiva, uma vez que muitos agressores sexuais, dentre os mais violentos, provêm de antigas pré-psicoses infantis "cicatrizadas" num modo de ser perverso. Nos casos mais graves, a afirmação narcísica fálica já não serve apenas à luta contra a angústia de castração e/ou de separação, nem mesmo à revalorização narcísica, mas sim para suturar uma identidade que está enfraquecida em sua própria constituição, desestabilizada pela adolescência.

\section{CONCLUSÕES}

A agressão dita sexual, de fato narcísico-fálica, evidencia assim uma elevação econômica da pulsão sexual violenta alimentada por forças pubertárias internas, bem como por forças externas excitantes demais, ou barradas de menos por mecanismos de proteção contra os estímulos - como a possível dimensão transgeracional incestuosa. Também o mau funcionamento qualitativo em que os arranjos narcísicos primários e secundários estão enfraquecidos - dentre os quais o trabalho da latência, que é de defesa e elaboração — torna particularmente difícil (se não perigoso) o comércio objetal com um outro, respeitado em sua diferença e em sua alteridade: a agressão sexual-fálica vem então a serviço da restauração narcísico-identitária. Na adolescência, em sujeitos que eram instáveis durante a infância, o agir toma o lugar da elaboração enfraquecida do afeto e do laço e, como para todos os distúrbios do comportamento, tal dinâmica é suscetível de tomar forma em função das respostas recebidas. Por essa razão, uma agressão sexual na adolescência, qualquer que seja, não deve nunca ser banalizada, e deve ser objeto de investigação psicodinâmica a que se siga uma proposta de consultas ou de cuidados apoiada no Judiciário. Falta ainda compreender por que a agitação ou a hiperatividade evoluem, em alguns casos, para uma delinquência não sexual, enquanto outros evoluirão para a agressão sexual-fálica. Parece-me que está em questão a intricação de fatores estruturais, familiares e contextuais. Se a dimensão familiar incestuosa apareceu como importante na minha coleção de casos, é preciso encarar que, para alguns, o acaso 
do contexto e da conjuntura (estou pensando nas situações festivas e grupais) tenha podido pesar no determinismo da passagem ao ato. Isso remete uma vez mais à importância de, no território da perícia judicial, não ficarmos encastelados numa perspectiva psicopatológica exclusiva, mas sim que devemos levar em conta uma dimensão criminológica mais ampla. ${ }^{10}$

Recebido em 1\%9/2008. Aprovado em 10/8/2009.

\section{REFERÊNCIAS}

AISENSTEIN, M. (2000) Michel Fain. Paris: PUf. (Psychanalystes d'aujourd'hui)

BALIER, C. (1988) Psychanalyse des comportements violents. Paris: PUF. (Le fil rouge)

BALIER, C. \& LEGENDRE, C. (1995) La compulsion au viol: une problématique psychique peu connue, Nervure, n.7, tome 8.

BALIER, C. (1996) Psychanalyse des comportements sexuels violents. Paris: PUF. (Le fil rouge)

BALIER, C. (Ed.) (2005) La violence en abyme. Paris: PUF.

BANGE F. \& MOUREN, M-C. (2005) Comprendre et soigner l'hyperactivité chez l'adulte. Paris: Dunod.

BERGER, M. (1999) L'enfant instable. Approche clinique et thérapeutique, Paris: Dunod.

BOUCHET-KERVELLA, D. (2001) "Existe-t-il des caractéristiques cliniques et psychopathologiques des pédophiles extra-familiaux adultes?”, in (2001), Psychopathologie et traitements des auteurs d'agression sexuelle. (Conférence de consensus, 22 et 23 novembre 2001). Paris: John Libbey Eurotext et Fédération Française de Psychiatrie, 101-112.

CAHN, R. (1998) L’adolescent dans la psychanalyse. L'aventure de la subjectivation. Paris: PUF.

CHABERT, C. (2003) Féminin mélancolique. Paris: PUF.

CHAGNON, J-Y (2000) Les troubles narcissiques chez les agresseurs sexuels. Psychologie clinique et projective, v.6-2000, p.265-278.

. (2004) A propos des aménagements narcissico-pervers chez certains agresseurs sexuels. Psychologie Clinique et Projective, v.10-2004, 147-186.

(2005a) Hyperactifs ou hypo-passifs? Hyperactivité infantile,

${ }^{10}$ Este texto pode ser proveitosamente completado pela leitura do capítulo "Distúrbios de comportamento, narcisismo fálico e luta contra a passividade na adolescência”, in: Cardoso, M. Rezende \& Marty, F. Destinos da adolescência. Rio de Janeiro: 7 Letras, 2008. 
agressions sexuelles à l'adolescence et nouveau malaise dans la civilisation. Psychiatrie de l'Enfant, n.1-2005, 31-88.

(2005b) Aux marges de la psychose: la perversité sexuelle. Bulletin de psychologie, Tome 58(6) /480/ novembre-décembre 2005, 663-670.

(2006) Plaidoyer pour un abord psychopathologique de l'hyperactivité. Perspectives Psy, v.45, n. 4, 331-338.

(2007) "Traumatisme, violence et agressions sexuelles à l'adolescence et chez le jeune adulte”, in MARTY, F. (Ed.) (2007) Traumatisme, violence et symbolization. Paris: In Press, 123-147.

(2008) "Distúrbios de comportamento, narcisismo fálico e luta contra a passividade na adolescência”. In: REZENDE CARDOSO M. \& MARTY, F. Destinos da adolescência. Rio de Janeiro: 7 Letras.

CIAVAlDINI A. (1999) Psychopathologie des agresseurs sexuels. Paris: Masson. \& BALIER C. (2000) Agresseurs sexuels: pathologies, suivis thérapeutiques et cadre judiciaire. Paris: Masson.

. (2005) "L’agir: un affect inachevé", in BOUHSIRA J. \& PARAT H. (2005) L’affect, Monographies de psychanalyse de la Revue Française de Psychanalyse, 137-161.

. (2006) "L'agir violent sexuel", in CHABERT, C., CIAVALDINI, A., JEAMMET, P., SCHENKERY, S. (2006) Actes et dépendances. Paris: Dunod, p.113-169.

DIATKINE, R. (1969) L'enfant prépsychotique. La psychiatrie de l'enfant, n. 2-1969, 413-446.

. (1985) "Introduction à la théorie psychanalytique de la psychopathologie de l'enfant et de l'adolescent”, in Traité de Psychiatrie de l'Enfant et de l'Adolescent, Tome 2, Ch. 63, 1039-1087.

FAIN, M. (1985) "Du corps érotique au corps malade: complexité de ce passage”, in FAIN, M.\& DEJOURS, C. (1985) Corps malade et corps érotique, Masson, p.123-135.

(1990) Virilité et anti-hystérie. Les rouleurs de mécanique, Revue Française de Psychanalyse, n. 5-1990.

(1991) "Préambule à une métapsychologie de la vie opératoire". Revue Française de Psychosomatique, n. 1-1991, 59-79.

GOLSE, B. \& DELION, P. (2003) “Instabilité psychomotrice chez l'enfant. Histoire des idées et réflexions actuelles”. EMC, 37-201-C-10.

GUTTON, P. (1991) Le pubertaire. Paris: PUF.

JEAMMET, P. (1985b) Actualité de l'agir. A propos de l’adolescence. Nouvelle Revue de Psychanalyse, 31, 201-222.

(1997) La violence à l'adolescence. Défense identitaire et processus de figuration. Adolescence, n. 15, 1-26.

. et al. (1998) "Délinquance infantojuvénile”. EMC (Psychiatrie), 37-216-G-10.

\& CORCOS, M. (2005) Evolution des problématiques à l'adolescence. L'émergence de la dépendance et ses aménagements. 2 ed. Rueil-Malmaison: Doin. JOLY, F. (Ed.) (2005) L'hyperactivité en débat. Ramonville St Agne: Erès.

KESTEMBERG E. \& KESTEMBERG, J. (1966) Contribution à la psychanalyse génétique. Revue française de psychanalyse, n. 5-6-1966, 580-713. 
LEGENDRE, C. (2003) Les adolescents auteurs de viols. Psychiatrie Française, n. 2-3, 2003, 104-115.

LAUFER, M. \& LAUFER E. (1989/1984) Adolescence et rupture de développement. Une perspective psychanalytique. Paris: PUF.

LEMITRE, S. \& COUTANCEAU, R. (2006) Trouble des conduites sexuelles à l'adolescence. Neuropsychiatrie de l'enfance et de l'adolescence, v.54 (3), 183-188.

MARTY, F. (Ed.) (2000) L'illégitime violence. La violence et son dépassement à l'adolescence. Ramonville St Agne : Erès.

(Ed.) (2007), Transformer la violence? Traumatisme et symbolisation, Paris: In Press.

MARTY, P. (1990) La psychosomatique de l'adulte. Paris: PUF. (Que sais je?)

MÉNÉCHAL, J. (Ed.) (2001) L’hyperactivité infantile. Débats et enjeux. Paris: Dunod.

MISES, R. (1990) Les pathologies limites de l'enfance. Paris: PUF. (Le fil rouge)

. (2001) Prefácio para MÉNÉCHAL J. (2001) L’hyperactivité infantile. Débats et enjeux. Paris: Dunod, p.XI-XVII.

(2004) “Troubles instrumentaux et psychopathologie". Neuropsychiatrie de l'enfance et de l'adolescence, v.52, n. 6, 353-355.

NEAU, F. (2001) La cruauté. Etude du fonctionnement psychique d'agresseurs sexuels, Thèse sous la direction du Pr. C. Chabert, Institut de psychologie. Université Paris 5, René Descartes.

(2005) Masculin maniaque, Psychologie clinique et projective. v.112005, 35-78.

PSYCHOPATHOLOGIE ET TRAITEMENTS DES AUTEURS D'AGRESSION SEXUELLE. (Conférence de consensus, 22 et 23 novembre 2001). Paris: John Libbey Eurotext et Fédération Française de Psychiatrie, p.101-112.

RACAMIER P. C. (1995) L'inceste et l'incestuel. Paris: Les éditions du collège. SCHNEIDER K. (1923) Les personnalités psychopathiques. Paris: PUF.

Jean Yves Chagnon

jean-yves.chagnon@univ-paris5.fr 